\title{
Effects of communication skills training courses on knowledge levels of the health workforce in Sulaimani
}

\begin{abstract}
Background and objective: Communication skills are one of the important and effective skills for healthcare providers. Health provider-patient communication is a core component of the health system and has a strong impact on health user satisfaction. This study aimed to explore the level of communication skills among health workforces, and the role of the training course on communication skills improvement.

Methods: This quasi-experimental study included 571 newly graduated participants of health workforces from a Sulaimani city center. Standard tools of communication skills were used for pre- and post-test evaluation through 5 hours of training course including 25-30 participants with a total of 24 training courses. Data collection was performed by the self-administered method. Descriptive statistics and analytical statistics were used to test statistical difference and associations.

Results: Minimum required for communication knowledge and skills are reported by the small percentage of studied participants $(12.6 \%)$ at the beginning of training. Comparing the mean scores of communication skills showed a statistically significant improvement (mean difference scores is 5.9) after the intervention. Significant communication skills improvement scores have been reported among youngest age groups and physicians.

Conclusion: Well-organized training courses in communication skills can increase the health workforces' rate of communication skills. Training in communication skills should be widely included during undergraduate studying and in-service training programs.
\end{abstract}

Keywords: Communication skills; Health care providers; Interpersonal skills; Communication training.

\section{Introduction}

Effective communication is a vital and cornerstone component in improving the quality of health care, decreasing malpractice, and medical error. ${ }^{1,2}$ When medical staff uses communication skills effectively, both they and their client's benefit. First, physicians understand their patient's needs and problems more precisely. ${ }^{3}$ Second, increasing the level of patient satisfaction toward health services, with a better understanding of their health problems, investigations, and treatments. Third, patients are following doctors instruction and line of management effectively, promote their behavior change positively and to increase drug adherence. ${ }^{4}$
Fourth, helping patients to decrease mental problems and stress and decrease their vulnerability for getting anxiety and depression. Finally, staffs' own wellbeing is improved. ${ }^{5-7}$ There are several basic principles of communication skills between health care providers and client, which are considered essential needs for providing the most effective communication. These include respect, mutual goals, a supportive environment, shared decision making, correct information, transparency, and a process of continuous learning..$^{8}$ Usually, most complaints from the clients and even general people toward health workforces in general and physicians in specific are the problems of communication not from the

* Department of Family and Community Medicine, School of Medicine, Faculty of Medical Science, University of Sulaimani, Sulaimani, I raq. 
clinical aspects. One of the commonest complaints is that the health service provider does not listen actively to them. Patients and clients want more and better information, and knowledge about their health problem and the results, more openness about the adverse effects of treatment, relief of pain and emotional distress, and advice on what they can do for themselves. ${ }^{9}$ Therefore, with consideration of the current situation and based on daily health provides communication skill experiences, the researcher realized that health care provider at different levels is not able to communicate effectively with patients and their surroundings. This may be due to lack of knowledge and skills in this field. The importance of communication skills related to health care performance led the researcher to study the impact of communication skills training on communication knowledge and skills improvement. The present study aimed to explore the knowledge level of communication and skills among health workforces, and the role of the training course on the communication skills improvement with exploring levels of improvement in relation to the sociodemographic characteristics.

\section{Methods \\ Study design \\ The design of this study was a quasi-experimental study.}

Sample size and duration of the study

Study participants were newly health workforce participants from different categories registered as new employees from the planning office of Sulaimani general directorate of health. All newly registered health workforces were included in the study; those who did not complete the training course were excluded from the study. Informing participants regarding time and place of training was arranged in cooperation with the planning department. The study was carried out from $20^{\text {th }}$ June 2014 to $1^{\text {st }}$ September 2015.

\section{The Intervention}

The communications training course intervention consisted of a 5-hour morning workshop in one day (8:30 am -1:30 pm), each training course was designed to train as a range between 23-30 participants for only each course. The total number of training courses were 24 training courses, the same material and methodology were used in all courses and by the same trainer. The training was managed scientifically by an academic and certified trainer in communication skills. Different techniques like role-playing, dissection, group work, brainstorming, and minilectures were used during training courses. The standard tool of communication skills was used as a measurement tool for pre and post-test evaluation. ${ }^{10}$ It is composed of fifteen questions; each question was a rating from 1 (for complete wrong choice) to 5 (for complete right choice). Mean scores ranking from 15 to 30 was regarded as a clear weakness in communication skills, mean scores of 36-55 means accepted and capable of doing their communication, and grade of excellent in communication skills was reported when total score was ranking from 56 to 75 . The total of scores was calculated by adding the score value of all questions. Data collection was performed by the distribution of the questionnaire at the beginning of the training course directly (pre-test), then similarly the same questionnaire was distributed to the participants at the end of the course (post-test).

\section{Statistical analysis}

Collected data were entered into an Excel sheet. After data cleaning process, data were entered into the statistical package for the social sciences (version 21). Descriptive analysis (frequencies and percentages) was performed for the demographic and aspects of communication skills of the participants. Cross-tabulation techniques with Chi-square statistic test were used to find an association between 
communication skills and demographics with the pre and post- test change in the skills. Also, the mean difference was calculated to find improvement in the communication skills of the pre and post-test evaluation. The t-tests (paired and two sample independent) and $F$ test (analysis of variance) were used to find significant difference and associations between studied variables.

\section{Ethical consideration}

All participants had provided informed consent. The study was conducted in full accordance with the ethical guidelines of the College of Medicine, University of Sulaimani.

\section{Results}

Table 1 shows the socio-demographic characteristics of the sample. Majority of participants $(67.3 \%)$ were young (20-29 years) with the mean age $29( \pm S . D=7.5)$ years, more than half of them were graduated from medical colleges (Medicine, Pharmacy, and Dentistry), nearly $25 \%$ were graduated from Medical School (Physicians). Half of the sample participants were resident inside Sulaimani city center. All participants were assessed for the evaluation of communication skills in pre and post-training to know the change (improvement) in the skills.

Table 1: Socio-demographic characteristics of the participants.

\begin{tabular}{lcc}
\hline Variables & Frequencies & Percentages \\
\hline Age groups in years & 384 & 67.3 \\
$20-29$ & 114 & 20 \\
$30-39$ & 73 & 12.7 \\
$\geq 40$ & & \\
Gender & 286 & 50.1 \\
Male & 285 & 49.9 \\
Female & & \\
Category of the participants & 141 & 24.7 \\
Physicians & 99 & 17.3 \\
Dentists & 81 & 14.2 \\
Pharmacists & 250 & 43.8 \\
Nurses (College and Institute) & & \\
& & \\
Residency & 288 & 50.4 \\
Inside city center & 173 & 30.3 \\
District & 110 & 19.3 \\
Sub-district & 571 & 100 \\
Total & & \\
\hline
\end{tabular}


Figure 1 shows that nearly $87 \%$ of participants were reported accepted or capable levels of communication skills, and only $12.6 \%$ reported excellent level of communication in the pretest evaluation, while the percentage of excellent levels of communication skills was significantly $(P=0.001)$ increased after conducting training course to $43.9 \%$, with reduction in the ratio of accepted or capable levels of communication from 86.1 (pretest) to $56.1 \%$ (post-test evaluation). Table 2 explores significant $(P=0.001)$ change (improvement) in total communication skill mean scores from 50.0 to 55.9. The youngest age groups (20-29 years) got significantly $(P=0.001)$ highest benefit and witnessed more improvement in their communication skills $(6.2 \pm 2.6)$ than the other age group (more than 40 years old), $(2.3 \pm 1.1)$.

Table 2: Overall communication skills scores in the pre and post-test evaluation

$\begin{array}{llll}\text { Training status } & \text { Mean } & \text { Std. Deviation } & P \text { value }\end{array}$

$\begin{array}{lccc}\text { Pre-test } & 50.0 & 6.6 & <0.001 \\ \text { Post-test } & 55.9 & 1.8 & \end{array}$

\begin{tabular}{|c|c|c|c|c|c|c|c|}
\hline \multirow{2}{*}{$\begin{array}{r}\% \\
100\end{array}$} & & \multicolumn{3}{|c|}{ = Weak $⿴$ Capable } & \multicolumn{2}{|c|}{ Excellent } & \\
\hline & & 86.8 & & & & & \\
\hline 80 & & & & & & & \\
\hline 60 & & & Pv: & lue $=<0.001$ & & 56.1 & \\
\hline 40 & & & & & & & \\
\hline 20 & & & 12.6 & & & & \\
\hline 0 & 0.5 & & & & 0 & & \\
\hline & & re-tes & & & & Post-te & \\
\hline
\end{tabular}

Figure 1: Communication skills levels of the participants in the pre and post test. 
Similarly, physicians were reported significantly $(P=0.001)$ high score improvement in their communication skills (7.1 \pm 2.6). However, no significant improvement in communication skills was identified in relation to gender, and residency of the participants $(P=0.518$, and 0.728 , respectively) as shown in Table 3.

\section{Discussion}

The results showing the general state of the participants' communication knowledge and skills were prominently low (excellent rate of communication was reported only among $12.6 \%$ of participants). This finding is not consistent with the research finding conducted in Poland during 2013 that reported a higher rate of communication skills among participants. ${ }^{11}$ This clearly indicated a defect in the educational training of the students during undergraduate study and lack of training in professional communication skills. The study also showed that training courses playing a significant role in improving communication knowledge and skills especially at the time of preemployment in the medical field, this finding as general is consistent with the results that are reported in other researches 12-14. This indicates that training courses are important techniques in overcoming shortages of communication knowledge and skills. Youngest age groups had got benefit and have been witnessed more improvement in their communication skills than the older age groups. 15 This finding is not similar to the result finding of other research that was performed in Turkey youngest participants are more aware regarding the importance of the communication skills due to new improvement in the curriculum of medical schools during previous five years, and they are more motivated to learn new skills, and they undertook more study-related activities to improve doctor-patient communication than older groups. A significant improvement in the

Table 3: Improvement (change) in communication skill scores after conducting training in relation to socio-demographic characteristics of the participants.

\begin{tabular}{lcc}
\hline Variables & $\begin{array}{c}\text { Improvements in communication skills } \\
\text { Mean } \pm \text { Standard deviation }\end{array}$ & $P$ value \\
\hline Age groups in years & $6.2 \pm 2.6$ & \\
$20-29$ & $3.3 \pm 1.6$ & \\
$30-39$ & $2.3 \pm 1.1$ & \\
$\geq 40$ & & 0.001 \\
Gender & $5.0 \pm 2.8$ & \\
Male & $5.4 \pm 1.4$ & \\
Female & & \\
Category of the participants & $7.1 \pm 2.6$ & \\
Physicians & $5.5 \pm 3.1$ & \\
Dentists & $4.8 \pm 1.0$ & \\
Pharmacists & $4.2 \pm 1.3$ & \\
Nurses (College and Institute) & & \\
Residencies & $5.4 \pm 2.3$ & \\
Inside city center & $5.2 \pm 2.6$ & \\
District & $4.7 \pm 1.4$ & \\
Sub-district & & \\
\hline
\end{tabular}


communication skills was reported among physicians than the other groups; these findings are similar to the results findings of other researches that were performed in the Netherlands and USA respectively. ${ }^{16,17}$ This finding can be explained that medical schools recognized the importance of interpersonal and communication skills in the practice of medicine and health services to the target groups. Physicians are more aware of the importance of communication skills during different aspects of doctor-patient interaction. Also, the highest capability of learning among physicians may explain high level in communication skills improvements than the others.

\section{Limitation of the study}

This study is considered a single communication skills training course designed for health workforces. The effectiveness of the training course was evaluated only at the end of the training course. It is important to include a number of factors that may limit the generalizability of the study results like duration of training, training models and techniques, and methods of evaluation of skills.

\section{Conclusion}

The results of this study show the benefits of communication skills training among health workforces despite the differences in specialties, age and education levels. Also, it provides an approach for learning and improving in practice for those interested in the health providers- clients communication skills.

\section{Competing interests}

The author declares no competing interests.

\section{References}

1. Michael L. Physician and Patient Communication: A Grounded Theory Analysis of Physician and Patient Web-Logs. MA thesis in Professional Communication. Southern Utah University, College of Humanities and Social Sciences; 2013.

2. Levinson W, Roter DL, Mullooly JP, Dull VT, Frankel RM. Physician-patient communication: the relationship with malpractice claims among primary care physicians and surgeons. JAMA 1997; 277(7):553-9.

3. Khodadadi E, Ebrahimi1 H, Moghaddasian S, Babapour J. The Effect of Communication Skills Training on Quality of Care, Self-Efficacy, Job Satisfaction and Communication Skills Rate of Nurses in Hospitals of Tabriz, Iran. J Caring Sci 2013; 2(1):27-37.

4. Jonathan SI, Suzanne KU, Juliet DR. Text book of Skills for Communicating with Patients.3rd ed. NewYork; CRC Publishers; 2016.

5. Roter DL, Hall JA, Kern DE, Barker LR, Cole KA, Roca RP. Improving physicians' interviewing skills and reducing patients' emotional distress. Arch Intern Med 1995; 155:1877-84.

6. Parle M, Jones B, Maguire P. Maladaptive coping and affective disorders in cancer patients. Psychol Med 1996; 26:735-44.

7. Ramirez AJ, Graham J, Richards MA, Cull A, Gregory WM. Mental health of hospital consultants: the effects of stress and satisfaction of work. Lancet 1995; 16:724-8.

8. Paget L, Han P, Nedza S, Kurtz P, Racine E, Russell S, et al. Patient-clinician communication: Basic principles and expectations. Institute of Medicine. Washington, DC. (Discussion Paper); 2011.

9. Peter M, Carolyn P. Key communication skills and how to acquire them. BMJ 2002; 325:697-700.

10. Mind tool team. How good are your communication skills? (Accessed January 5, 2019 at https://www.mindtools.com/pages/article/ newCS_99.htm)

11. Anna $W$, Mirosław J. Selected aspects of a professional doctor-patient communication education and practice. Ann Agric Environ Med 2013; 20(2):373-9.

12. Cantillon $\mathrm{P}$, Jones $\mathrm{R}$. Does continuing medical education in general practice make a difference? BMJ 1999; 318:1276-9.

13. Peck C, McCall M, McLaren B, Rotem T. Continuing medical education and continuing professional development: international comparisons. BMJ 2000; 320:432-5.

14. Grol R. Improving the quality of medical care: building bridges among professional pride, payer profit and patient satisfaction. JAMA 2001; 286:2578-85.

15. Mehmet A, Orhan C, Levent S, Emel D, Bikem $\mathrm{H}$, Hayri $\mathrm{C}$, et al. Communication Skills Training For Emergency Nurses. Int J Med Sci 2011; 8(5):397-401.

16. Hulsman RL, Ros WJG, Winnubst JAM, Bensing JM. Teaching clinically experienced physicians communication skills. A review of evaluation studies. Med Educ1999; 33:655-68.

17. Cegala DJ, Lenzmeier-Broz S. Physician communication skills training: a review of theoretical backgrounds, objectives and skills. Med Educ 2002; 36(11):1004-16. 